\title{
LETTERS
}

\section{Peptostreptococcal pericarditis complicating anti-tumour necrosis factor $\alpha$ treatment in rheumatoid arthritis}

\author{
S Harney, F D O'Shea, O FitzGerald
}

Ann Rheum Dis 2002;61:653-654

$\mathrm{R}$ heumatoid arthritis (RA) is a common cause of disability and deformity for which treatment is often of limited value in controlling the disease process and outcome. ${ }^{1}$

Infliximab (chimeric antibody to tumour necrosis factor $\alpha$ $(\mathrm{TNF} \alpha)$ ) is clearly efficacious in up to $70 \%$ of patients, but treatment may be complicated by the development of infections that are occasionally serious and life threatening. Pooled analysis reported a $21 \%$ incidence of infection among 453 patients treated with infliximab compared with an $11 \%$ incidence in 109 placebo recipients. ${ }^{2}$ Infections considered serious occurred in $3.4 \%$ and $1.8 \%$ of patients, respectively. As of August 2001, 84 of 170000 patients treated with infliximab world wide had developed active tuberculosis, including 14 deaths.

\section{CASE REPORT}

Here we present the case of a 57 year old man with a five year history of RA who was admitted with a two week history of anorexia and nausea accompanied by pale stools and dark urine. Previous treatment for RA had included Salazopyrin (3 $\mathrm{g} /$ day), methotrexate (20 mg/week), cyclosporin $(5 \mathrm{mg} / \mathrm{kg}$ ), and a matrix metalloproteinase inhibitor (Trocade), with inadequate response to each of these agents..

Treatment with infliximab at a dose of $3 \mathrm{mg} / \mathrm{kg}$ was started in combination with methotrexate $7.5 \mathrm{mg} /$ week and Deltacortril $5 \mathrm{mg} /$ day. He responded well to this treatment regimen. Three weeks before his admission, he reported feeling very well. He had low grade synovitis in his metacarpophalangeal joints only, both erythrocyte sedimentation rate (ESR) and C reactive protein (CRP) were normal, as were full blood count and liver function studies. The patient's occupation was that of a distributor of farm equipment.

On admission, he was apyrexial, tachycardiac, and normotensive. He was icteric with a $5 \mathrm{~cm}$ hepatomegaly. Clinical examination, including cardiovascular and respiratory systems, was normal. Poor oral hygiene was noted. Initial investigations showed a raised white cell count of $13.5 \times 10^{9} / 1$ with a neutrophilia; ESR $78 \mathrm{~mm} / \mathrm{lst}$ h, CRP $159 \mathrm{mg} / \mathrm{l}$, and transaminases were grossly abnormal with an aspartate aminotransferase of $1558 \mathrm{U} / \mathrm{l}$ and an alanine aminotransferase of $1525 \mathrm{U} / \mathrm{l}$. An electrocardiogram was normal and a chest radiograph was also normal apart from showing cardiomegaly. Abdominal ultrasound showed hepatomegaly with minimal ascites. The initial diagnosis was drug induced hepatitis. He admitted to consumption of 20-25 units of alcohol weekly.

The day after admission, the patient collapsed and became hypotensive. An echocardiogram showed a large pericardial effusion. A computed tomographic (CT) scan of the thorax (fig 1) confirmed the effusion and also showed bilateral pleural effusions. He proceeded to pericardiocentesis and one litre of purulent fluid was drained. Treatment was started empirically with teicoplanin and gentamicin. Pericardial fluid subsequently grew peptostreptococci, and the antibiotics were changed to amoxycillin $2 \mathrm{~g}$ four times a day based on sensitivities. A repeat echocardiogram and CT scan at two

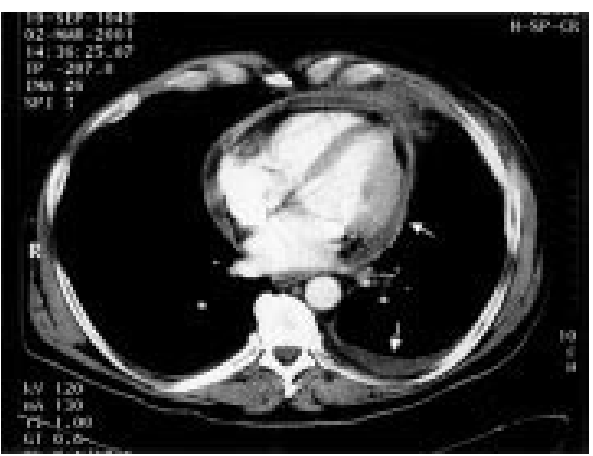

Figure 1 CT scan of the thorax showing marked pericardial effusion (arrow) and bilateral pleural effusions (left greater than right) (arrow): mediastinal windows.

weeks showed a residual pericardial effusion, and a fenestration procedure was carried out before the patient's discharge. Three months after discharge a further echocardiogram showed pericardial thickening, but no effusion was present.

Treatment with infliximab and methotrexate was withheld at the time of the patients' presentation with purulent pericarditis, but within two months his arthritis flared, necessitating an increase in steroids and the introduction of leflunomide.

His presentation initially suggested a drug-induced hepatitis. The subsequent development of pericardial tamponade was fortunately promptly recognised and treated, leading to a satisfactory outcome in this patient.

\section{DISCUSSION}

Peptostreptococcus is a rare anaerobe most commonly isolated from peritoneal fluid, followed by joint fluid, abscess and endometrial materials, soft tissue biopsy, and draining material. ${ }^{3}$ To date, no cases of pericarditis caused by this organism have been reported. Although poor oral hygiene was evident, it is possible that this patient's occupation exposed him to the organism.

With increased use of anti-TNF $\alpha$ treatment, serious infections have been increasingly recorded. Although treatment successfully controlled the infection, this serious adverse event further highlights concerns about anti-TNF $\alpha$ treatment and emphasises the need for vigilance and prompt treatment.

\section{Authors' affiliations}

S Harney, F D O'Shea, O FitzGerald, Department of Rheumatology, St Vincent's University Hospital, Elm Park, Dublin 4, Ireland

Correspondence to: Dr ○ FitzGerald; rheumatologysvh@eircom.net

Accepted 18 December 2001 


\section{REFERENCES}

1 Maini RN, Elliott M, Brennan FM, Williams RO, Chu CQ, Paleolog E, et al. Monoclonal anti TNF alpha antibody as a probe of pathogenesis and therapy of rheumatoid disease. Immunol Rev 1995; 144:195-223.
2 Hanauer SB. Safety of infliximab in clinical trials. Aliment Pharmacol Ther 1999;13(suppl 4):16-22.

3 Durmaz B, Durmaz R, Tastekin N. Evaluation of culture results of specimens from patients with suspected anaerobic infection. New Microbiol 1999;22:155-9.

\section{Alopecia in Wegener's granulomatosis}

\section{Hidalgo-Tenorio, J M Sabio, J Jiménez-Alonso}

A lopecia is not a distinctive clinical sign in Wegener's granulomatosis and, as far as we know, to date no cases have been published describing this phenomenon.

\section{CASE REPORT}

We present the case of a 54 year old woman diagnosed with Wegener's granulomatosis, who in the first stage of her disease had alopecia and improved after treatment with cyclophosphamide and prednisone.

Nine months before her admission to our service, she had had paraesthesias, and leg pain and dysfunction. Electromyography showed some signs of sensorimotor polyneuropathy. She was given prednisone for 10 days (90 mg/day) and improved partially. Five months later, she started coughing up haemoptysic sputum, and had arthralgias in both hands, constitutional symptoms, and intense and diffuse hair loss (traction positive). Her temperature was $36.5^{\circ} \mathrm{C}$, blood pressure 130/60 $\mathrm{mm} \mathrm{Hg}$, respirations 16, pulse 80 beats/min, and her weight was $44 \mathrm{~kg}$.

Physical examination showed $2 \mathrm{~cm}$ abdomen hepatomegaly and leg distal muscular atrophy. 4/5 upper limb distal weakness, normal positional and vibratory sensitivity, paretic-spastic walk, and deep tendon reflexes increased diffusely with clonic reply. The erythrocyte sedimentation rate was $91 \mathrm{~mm} / \mathrm{lst} \mathrm{h}$, platelets $678 \times 10^{9} / \mathrm{l}$, C reactive protein $229 \mathrm{mg} / \mathrm{l}$, rheumatoid factor $1 \mathrm{U} / \mathrm{ml}$. A chest $x$ ray examination showed a bilateral interstitial pattern with multiple fibre tracts of hilar origin and ulterior segment atelectasis. Chest computed tomography showed three small nodules located in the front segment of the right upper lobe and right middle lobe-one was $5 \mathrm{~cm}$ and the other two were $1 \mathrm{~cm}$. We also noted scarring fibre tracts in the left upper lobe and lower lobe back basal regions. The antineutrophil cytoplasmic antibody cANCA titre was 1/160 U/ml (normal range 0-20), proteinase 3 was $133 \mathrm{U} / \mathrm{l}$, and myeloperoxidase, antinuclear antibodies, SSA/Ro, SSB/La, RNP, and Scl-70 were negative. ECA was $23 \mathrm{U} / \mathrm{l}$ (normal range 8-55).

A diagnosis of Wegener's granulomatosis was made. The patient was treated with prednisone $(60 \mathrm{mg} /$ day $)$ with normal tapering and 10 monthly cyclophosphamide pulses (each 500 $\mathrm{mg} / \mathrm{m}^{2}$ each). The patient's symptoms, including respiratory, neurological involvement, and alopecia, improved. As Langford et al have described, ${ }^{1}$ after the last pulse of cyclophosphamide we added methotrexate (10 mg/week); the patient's condition deteriorated and she had mild atrophy on her right leg lateral side and slight alopecia, and the proteinase 3 level reached $100 \mathrm{U} / \mathrm{l}$. We stopped methotrexate and gave oral cyclophosphamide ( $2 \mathrm{mg} / \mathrm{kg} /$ day); the neurological symptoms and alopecia then improved (traction negative) and proteinase 3 became normal.

\section{DISCUSSION}

Wegener's granulomatosis is one type of vasculitis whose mortality rate, if not treated, can be high $(82 \%)$ with a survival rate of 5-12 months. ${ }^{2}$ Treatment of this disease with cyclophosphamide has increased the survival rate of patients, ${ }^{3}$ and the daily combination of high doses of prednisone and oral cyclophosphamide has proved to be very effective in more than $90 \%$ of cases, especially when used from its initial stage to its remission,. ${ }^{1}$ Because this combination has many side effects (in $42 \%$ of cases), other alternatives may need to be used, such as high doses of daily prednisone and monthly cyclophosphamide pulses, which have a higher degree of remission with fewer side effects, but also more relapses. ${ }^{4}$ The use of methotrexate for maintenance of remission is a successful alternative to oral cyclophosphamide with a lower percentage of relapses $(16 \%),{ }^{1}$ but in our patient that regimen was ineffective. Cyclophosphamide is an alkylating agent with cytotoxicity and immunosuppressive activity. Its main side effects are leucopenia, infections, vomiting ${ }^{5}$ and haemorrhagic cystitis. ${ }^{6}$ Alopecia is deemed to be one of the most common side effects of cyclophosphamide. ${ }^{5}$ The side effects are directly related to the doses given, so that these can be reduced with a weekly dose of a $500 \mathrm{mg}$ pulse given for three months ${ }^{2}$; the length of exposure to the drug may be another factor to take into account. ${ }^{1}$ In our patient, alopecia appeared during the active stage of the disease. Once corticosteroids and cyclophosphamide were given, we were able to control the disease activity and cranial hair loss. We believe that the pilose follicle is another organ which nay be affected in Wegener's granulomatosis by a vasculitis of the scalp vessels; and although we did not perform a scalp biopsy, it seems likely that this disease might have caused the patient's hair loss.

The interesting aspect of this case is that the patient had Wegener's granulomatosis and alopecia and she improved with a treatment which included prednisone and cyclophosphamide.

Authors' affiliations

C Hidalgo-Tenorio, J M Sabio, J Jiménez-Alonso, Service of Internal Medicine, University Hospital "Virgen de las Nieves", Granada, Spain

Correspondence to: Dr J Jiménez-Alonso, Hospital Universitario Virgen de las Nieves, Avda de las Fuerzas Armas, No 2, Granada, 18014 Spain; jualso@hvn.sas.cica.es

Accepted 18 December 2001

\section{REFERENCES}

1 Langford CA, Talar-Williams C, Barron KS, Sneller MC. A staged approach to the treatment of Wegener's granulomatosis: induction of remission with glucocorticoids and daily cyclophosphamide switching to methotrexate for remission maintenance. Arthritis Rheum 1999;42:2666-73

2 Martin-Suarez I, D'Cruz D, Mansoor M, Fernandes AP, Khamashta MA, Hughes GR. Immunosuppressive treatment in severe connective tissue diseases: effects of low dose intravenous cyclophosphamide. Ann Rheum Dis 1997;56:481-7.

3 Fauci A S, Katz P, Haynes BF, Wolf SM. Cyclophosphamide therapy of severe systemic necrotizing vasculitis. N Engl J Med 1979;301:235-8. 
4 Guillevin L, Cordier JF, Lhote F, Cohen P, Jarrousse B, Royer I, et al. Prospective, multicenter, randomized trial comparing steroids and pulse cyclophosphamide versus steroids and oral cyclophosphamide in the treatment of generalized Wegener's granulomatosis. Arthritis Rheum 1997;40:2187-98
5 Le Thi Huong D, Papo T, Piette JC, Wechsler B, Bletry O, Lamas G, et al. Monthly intravenous pulse cyclophosphamide therapy in Wegener's al. Monthly intravenous pulse cyclophosphamide therap

6 Ahmed AR, Hombal SM. Cyclophosphamide (Cytoxan). A review on Ahmed AR, Hombal SM. Cyclophosphamide (Cytoxan). A review
relevant pharmacology and clinical uses. J Am Acad Dermatol 1984; 11:1115-26.

\title{
Paediatric Behçet's disease in France
}

\author{
I Koné-Paut, A Gorchakoff-Molinas, B Weschler, I Touitou
}

$(2$ ur objective was to assess the increase in the number of children with Behçet's disease in France. To our knowledge, this survey is the most extensive reported from a single country.

Children with Behçet's disease from any part of France were referred to one of three medical centres: Marseille, Montpellier, and Paris. Information was obtained from the medical charts and from the patient's interview. A specific questionnaire was designed to determine the following demographic features: sex, age, city of residence, ethnicity, and familial history with complete pedigree; and the clinical variables: oral aphthous ulcers, genital ulceration, skin lesion, skin hypersensitivity plus other organ involvement-nervous system, gastrointestinal tract, eye, vessels, lungs, heart, joints, genitourinary tract, and fever. The date of onset of the disease was recorded together with the date of appearance of each symptom, and the date at which the patient met the international criteria for Behçet's disease. ${ }^{1}$ A specific database was set up.

Fifty five children with Behçet's disease met the international criteria before the age of 16 years: 33 white subjects (27 French), nine North Africans, five Turks, three West Indians, three mixed white/North African subjects, one Asian, and one Ashkenazi Jew. The male to female ratio was 0.89 . The mean age of onset was 7.5 years (median 8 years, SD 4.3). The mean age at which patients met the criteria for Behçet's disease was 11.6 years (median 12, SD 3.7; fig 1). The mean time between the appearance of the first and last criterion was 3.5 years (median 3, SD 3.7).

Initial symptoms were oral ulcers in 41 (74\%) (at a mean age of 6.8 years), genital ulcers in $13(24 \%)$ (at a mean age of 6.8 years), bipolar aphthosis in nine $(16 \%)$, skin lesions in eight (14\%), and uveitis in two (4\%). At least two criteria were present in nine $(16 \%)$ patients.

Recurrent oral ulcers were present at a mean age of 7.44 years. Genital ulceration occurred in 43 (79\%) patients, at a mean age of 10.8 years. Cutaneous signs included erythema nodosum (26\%), necrotic folliculitis (38\%), and aphthosis (14\%). Ocular signs were uveitis (36\%), retinal vasculitis (24\%), conjunctivitis (17\%), papilloedema (7\%), and keratitis (3\%). Arthralgia was the main articular sign, arthritis was present in $17 \%$ of patients. Headaches were common (35\%) and associated with aseptic meningitis (10\%), benign intracranial hypertension $(10 \%)$, and hemiparesis in two patients. Abdominal pain was reported in $40 \%$ of cases, with digestive ulceration in $14 \%$. Ulcerative colitis was diagnosed in one patient. Venous thrombosis occurred in $21 \%$ of patients.

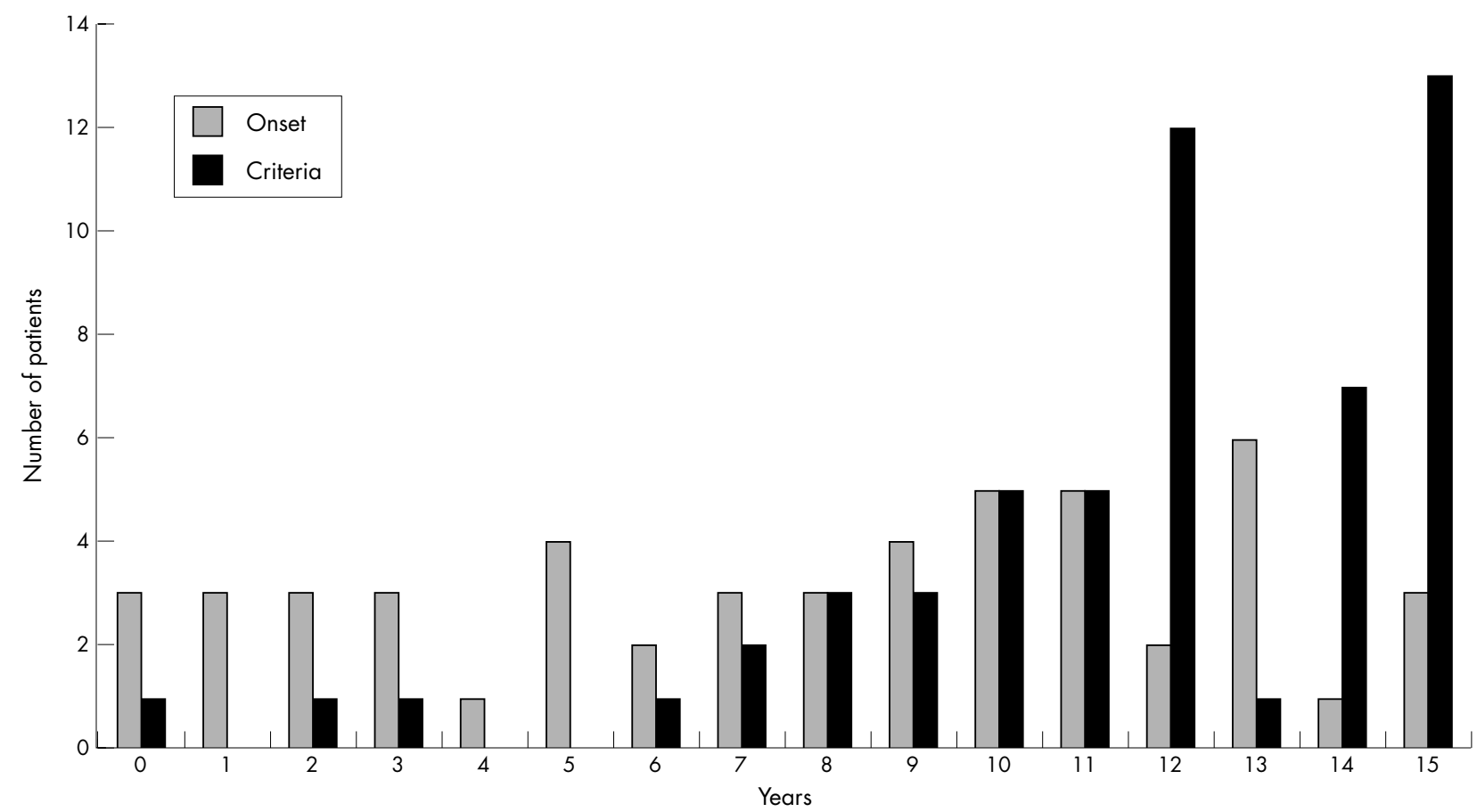

Figure 1 Age at which the first symptom appeared and age at which the children satisfied the criteria for Behçet's disease. 
One 13 year old boy died of multiple deep vein thrombosis. Familial aggregation was present in four families which included eight patients (9\%).

The epidemiology of paediatric Behçet's disease is difficult to evaluate because there is no formal agreement about the age of onset or the age of completed disease. ${ }^{23}$ Previous epidemiological studies have shown that the proportion of patients in whom the onset of symptoms occurs under the age of 16 years varies from $3 \%$ to $24 \% .^{4-7}$

Selection of patients according to international criteria gave high percentages of patients with mucocutaneous and ocular symptoms (reaching 60\%, of which $36 \%$ were uveitis). The spread of clinical signs in our patients was similar to that obtained by other studies for patients of the same mean age and recruited similarly. The familial occurrence of BD, 9\%, has been reported to be high in children and also in patients from endemic areas such as Turkey, Korea, and Tunisia. ${ }^{8-10}$ Therefore genetic linkage studies are needed to examine the genetic component of Behçet's disease further.

The number of recognised cases of Behçet's disease in children in France is increasing, probably reflecting an increase in doctors' awareness of this disease. Worldwide collaborations are now needed to delineate this subgroup of patients and to establish accurate sets of criteria.

\section{ACKNOWLEDGEMENTS}

Contributing doctors and nurses: Christine Bodemer, Brigitte Chabrol, Michel Cointin, Louis David, Paul Fisbach, Ariane Freychet, Catherine Glastre, Eric Grouteau, Jean Robert Harlé, Gilles Kaplanski, Irène Lemelle, Alain Le Quellec, Josette Mancini, Anne Marie Prieur, Michèle Monticelli, Pierre Quartier dit Maire, Danièle Sommelet, Jean Louis Stephan; The Association Behçet "B7" France and the Assistance Publique Hôpitaux de Marseille.

\section{Authors' affiliations}

I Koné-Paut, A Gorchakoff-Molinas, Department of Paediatrics, CHU Nord, Marseilles, France

B Weschler, Department of Internal Medicine, Hôpital Pitié Salpétrière, Paris, France

I Touitou, Laboratory of Genetics, Hôpital Arnaud de Villeneuve, Montpellier, France

Correspondence to: Dr I Koné-Paut, Hôpital Nord, Department of Paediatrics, Chemin des Bourrelys, 13915 Marseille cedex 20, France; ikone-pau@mail.ap-hm.fr

Accepted 17 January 2002

\section{REFERENCES}

1 International study group for Behçet's disease. Criteria for the diagnosis of Behçet's disease. Lancet 1990;335:1078-80.

2 Bang D, Han Yoon K, Chung HG, Cho EU, Lee ES, Lee S. Epidemiological and clinical features of Behçet's disease in Korea. Yonsei Med J 1997:38:428-36.

3 Zouboulis CC, Kötter I, Djawari D, Kirch W, Khol PK, Ochsendorf FR, et al. Epidemiological features of Adamantiades Behçets disease in Germany and in Europe. Yonsei Med J. 1997;38:411-22.

$4 \mathrm{Kim}$ DK, Chang SN, Bang D, Lee ES, Lee S. Ćlinical analysis of 40 cases of childhood onset Behçet's disease. Pediatr Dermatol 1994;11:95-101.

5 Sarica R, Azizerli G, Kose A, Disci R, Ovul C, Kural Z. Juvenile Behçet's disease among 1784 Turkish Behçet's patients. Int J Dermatol 1996;35:109-11

6 Benamour S, TakTak T, Moudatir A, Hamdani M, Mikou N, Hadj Khalifa $\mathrm{H}$, et al. Juvenile Behçet's disease and juvenile onset Behçet;s disease in Morocco. In: Proceedings of the $7^{\text {th }}$ international congress on Behçet's disease. Reggio Emilia 1998:176.

7 Treudler RR, Orfanos CE, Zouboulis CC. Twenty eight cases of juvenile onset Adamantiades Behçet's disease in Germany. Dermatology 1999; 199:15-19

8 Koné-Paut I, Geisler I, Wechsler B, Ozen S, Ozdogan H, Rozenbaum $M$, et al Characteristics of familial aggregation in Behçet's disease: high frequency of $\mathrm{BD}$ in siblings and parents of pediatric probands. J Pediatr 1999;135:89-93.

9 Gul A, Inanc M, Ocal L, Aral O, Konice M. Familial aggregation of Behçet's disease in Turkey. Ann Rheum Dis 2000;59:622-5.

10 Fresko I, Soy M, Hamuryudan V, Yurdakul S, Yavuz S, Tuner Z, et al. Genetic anticipation in Behçet's syndrome. Ann Rheum Dis 1998;57:45-4

\title{
Intra-articular and soft tissue injections: assessment of the service provided by nurses
}

\author{
J Edwards, B Hannah, K Brailsford-Atkinson, T Price, T Sheeran, D Mulherin
}

L ocal steroid injections have traditionally been given by doctors in rheumatology practice, with varying accuracy and success. ${ }^{1-3}$ The first joint injection course for nurses approved by the English National Board (ENB) was established at Cannock Chase Hospital in 1995, jointly led by a rheumatology consultant and nursing sister, and has run annually since then (ENB-N78). ${ }^{4}$ Over 50 nurses have completed the course, including many from this unit. They now give an increasing proportion of these injections at this hospital (following medical prescription), releasing doctors for other activities. Our audit assessed this service increasingly provided by nurses, measuring the frequency and type of nurse injection and patient satisfaction. Injections given by nurses and doctors at this unit were compared, as we required a standard of service from the nurses at least equal to that of the doctors.

The audit included all patients who underwent an intra-articular or soft tissue cortiocosteroid injection at this hospital over one calendar month. Injectors recorded their professional background and the site of injection(s). After the
Table 1 Number of local corticosteroid injection at different anatomical sites performed by nurses and doctors

\begin{tabular}{lrrr}
\hline Site & Nurse & Doctor & Total \\
\hline Subacromial space & 32 & 18 & 50 \\
Glenohumeral joint & 5 & 4 & 9 \\
Elbow joint & 3 & 2 & 5 \\
Wrist joint & 14 & 5 & 19 \\
Carpometacarpal joint & 0 & 2 & 2 \\
Knee joint & 35 & 12 & 47 \\
Ankle joint & 14 & 2 & 16 \\
Subtalar joint & 0 & 4 & 4 \\
Trochanteric bursa & 1 & 1 & 2 \\
Other & 10 & 6 & 16 \\
& & & 170 \\
Total & 114 & 56 & 170 \\
\hline
\end{tabular}



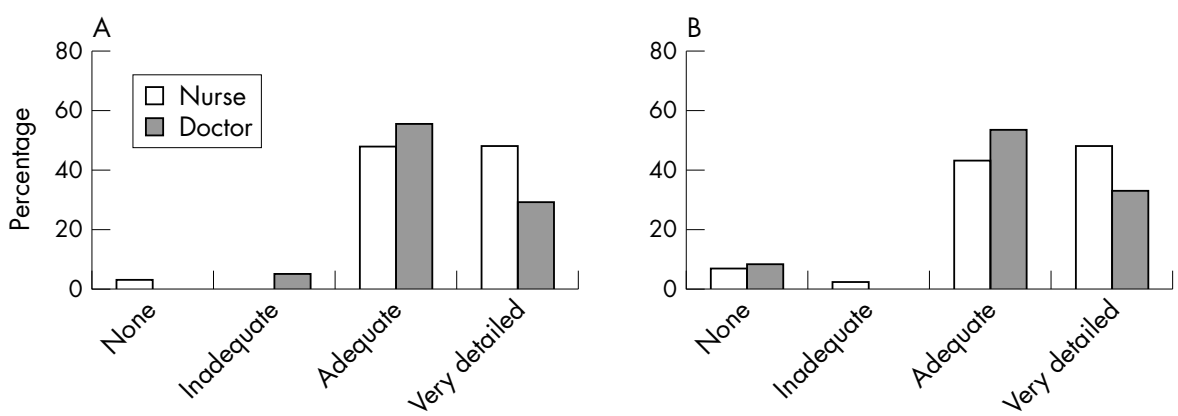

Figure 1 Quality of information provided to a patient by a nurse or doctor injector as rated by the patient before (A) or after (B) local corticosteroid injection. Ratings were provided by 38 patients who received their injections from doctors and 58 patients who received their injections from trained nurses.

injection, the patient completed an anonymous questionnaire in their home within 3-7 days for return by prepaid envelope. This also recorded the injector's professional background; the patient's opinion of the adequacy of the information given before and after the injection (on a four point scale, from "no information" to "very detailed information"); the comfort (on a four point scale, from "very comfortable" to "very uncomfortable") and efficacy (on a four point scale, from "very helpful" to "made worse") of the procedure; their overall satisfaction (marked on a $10 \mathrm{~cm}$ visual analogue scale (VAS)); and the professional group from whom they would prefer to receive any future injections. The approval of the local research ethics committee was given for this audit.

In one month, 170 corticosteroid injections were given to 103 patients: trained nurses gave $114(67 \%)$ of these injections to 63 patients. Nurses gave a mean (range) of 1.8 (1-8) injections to each patient compared with $1.4(1-4)$ given by doctors. Nurses gave most of the ankle, knee, wrist, elbow, glenohumeral, and subacromial injections (table 1). Doctors gave all subtalar and carpometacarpal joint injections. Ninety three $(90 \%)$ completed questionnaires were returned by patients. Almost all (96\%) described preinjection information as "adequate" or "very detailed", but more described it as "very detailed" when given by a nurse $(48 \%)$ than when given by a doctor (32\%) (fig 1). A greater proportion also described postinjection information as "very detailed" when given by a nurse $(47 \%$ v $34 \%$ ) (fig 1). Most (93\%) described the injection as "fairly comfortable" or "very comfortable" but were more likely to have described the injection given by a nurse as "very comfortable" (61\% v 43\%). Almost all the injections given by both nurses and doctors were described as "helpful" or "very helpful" (93\% and 88\%, respectively). Overall satisfaction of injections given by nurses and doctors was similar (mean (range) VAS $8.0(1.1-10.0) \mathrm{cm}$ and $7.8(0.6-10) \mathrm{cm}$, respectively). Only one patient injected by a nurse expressed a preference for any future injections to be given by a doctor; the rest preferred a nurse $(38 \%)$ to give any future injections or had no preference.

This audit confirmed that trained nurses were performing the vast majority of local corticosteroid injections at this unit and that their standards were at least as good as those of doctors. Patients felt well informed by nurse injectors, found their injections were effective, were highly satisfied with their treatment, and were willing to have further treatment from nurses, if necessary. The results show that trained nurses can deliver a service previously provided by doctors in training, whose working hours are now greatly restricted.
There might be concerns about the experience acquired by such doctors during their rheumatology attachment, but further audit has shown that they now learn the techniques of steroid injection largely from trained nursing staff (results not shown). Rheumatology nurses now fulfil a wide range of roles in education, counselling, monitoring, and giving treatment. ${ }^{5}$ Debate continues over whether such developments represent progress or a dilution of the nurturing role traditionally ascribed to nurses. ${ }^{67}$ The cost effectiveness of an injection service provided by nurses was not considered by this audit and would be influenced by salary and patient throughput. The length of time spent with patients during this audit was not recorded, but it is worth noting that nursing staff were performing multiple intra-articular injections on some patients, which is time-consuming in itself and certainly does not represent "cherry picking" the easy cases.

\section{ACKNOWLEDGEMENT}

The authors acknowledge and thank Dr A Hassell, consultant rheumatologist, for his foresight and determination in establishing the ENB-N78 joint injection course.

\section{Authors' affiliations}

J Edwards, B Hannah, K Brailsford-Atkinson, T Price, T Sheeran, D Mulherin, Department of Rheumatology, Cannock Chase Hospital, United Kingdom

Correspondence to: Dr D Mulherin, Department of Rheumatology Cannock Chase Hospital, Brunswick Road, Cannock, WS 11 2XY, UK; diarmuid.mulherin@msgh-tr.wmids.nhs.uk

Accepted 19 December 2001

\section{REFERENCES}

1 Dixon A, Emery P. Local injection therapy in rheumatic diseases. 4th ed. Basle: Eular Publishers, 1992.

2 Haslock I, MacFarlane D, Speed C. Intra-articular and soft tissue injections: a survey of current practice. Br J Rheumatol 1995;34:449-52.

3 Eustace JA, Brophy DP, Gibney RP, Bresnihan B, FitzGerald O. Comparison of the accuracy of steroid placement with clinical outcome in patients with shoulder symptoms. Ann Rheum Dis 1997;56:59-63.

4 Edwards J, Hassell A. Intra-articular and soft tissue injections by nurses: preparation for expanded practice. Nurs Standard 2000;1 4:43-6.

5 Hill J. The expanding role of the nurse in rheumatology. Br J Rheumatol 1997:36:410-12.

6 Gardiner PV. Nurse practitioner clinics. Br J Rheumatol 1994;33:893.

7 A Carr, ed. Defining the extended clinical role for allied health professionals in rheumatology. Chesterfield: The Arthritis Research Campaign, 2001 


\title{
Manual jobs increase the risk of patients with ankylosing spondylitis withdrawing from the labour force, also when adjusted for job related withdrawal in the general population
}

\author{
A Boonen, A Chorus, R Landewé, D van der Heijde, H Miedema, $\mathrm{H}$ van der Tempel, \\ Si van der Linden
}

Ann Rheum Dis 2002;61:658

n 1997 we studied labour force participation among 658 Dutch patients with ankylosing spondylitis (AS). ${ }^{1}$ In those who had a paid job before onset of disease $(n=529)$, age and sex adjusted withdrawal rate was 3.0 times (95\% CI 2.5 to 3.6 ) higher than expected in the general Dutch population. ${ }^{2}$ Within patients with AS, those with a manual job had a 2.3 (95\% CI 1.5 to 3.4) times increased risk of withdrawal compared with those with a non-manual job after correction for age at onset of disease, gender, educational level, and coping strategies. ${ }^{2}$ However, the question remained whether a manual job was a specific risk factor for withdrawal from work in patients with AS or if a manual job is a non-specific risk factor for withdrawal in every working subject.

Recently, Dutch population figures for 1998 on withdrawal from the labour force, for the same work categories as used in our study, became available (Dutch Bureau of Statistics). Therefore, we were then able to calculate the job adjusted ratios for withdrawal from the labour force in patients with AS by comparing the job-specific annual withdrawals in patients with those from the general population. Five major classes of work were distinguished: agriculture, industry, transport, commerce, and services/management. The first three classes were later grouped as manual jobs and the last two classes as non-manual jobs. This classification has some limitations because jobs like housekeepers and waiters are also included within the servicing jobs and therefore considered as non-manual jobs. However, this was similar in patients and in controls. All data were stratified by gender. The 95\% CIs for the ratios were calculated using Poisson's distribution.

Table 1 presents for each job class, the observed rates of withdrawal from the labour force as well as the ratios when compared with the general population. While the overall risk for a patient with AS to withdraw from the labour force is 3.0 (95\% CI 2.5 to 3.6 ) times higher than expected in the general population, this risk is 4.9 (95\% CI 3.5 to 5.9 ) times higher for those with a manual job versus 2.2 (95\% CI 1.6 to 2.7) times higher for those with a non-manual job. The observed effect was stronger in male than in female patients, probably because of the smaller number of female patients in the study sample. In the general population withdrawal rates were not significantly different among the professional classes studied either for men or for women.

We conclude that patients with AS with a manual job have an increased risk for withdrawal from the labour force, also when adjusted for job related withdrawal in the general population.

\section{ACKNOWLEDGEMENT}

The authors acknowledge the Dutch rheumatologists participating in the Standardised Diagnositic Register of Rheumatic Diseases and all patients who took part in this study.

\section{Authors' affiliations \\ A Boonen, $R$ Landewé, $D$ van der Heijde, Si van der Linden, Department of Internal Medicine, Division of Rheumatology, University Hospital Maastricht, The Netherlands \\ A Chorus, Division of Public Health, TNO Prevention and Health, Leiden, The Netherlands \\ R Landewé, Atrium Medical Centre, Heerlen, The Netherlands \\ D van der Heijde, Limburg University Centre, Diepenbeek, Belgium \\ H Miedema, Netherlands Expert Centre for Workrelated Musculoskeleta Disorders, University Hospital Dijkzigt and Erasmus University Rotterdam, The Netherlands \\ H van der Tempel, Maasland Ziekenhuis Sittard, The Netherlands}

Correspondence to: $\mathrm{Dr}$ A Boonen, Department of Internal Medicine, Division of Rheumatology, University Hospital Maastricht, PO Box 5800, 6202 AZ Maastricht, The Netherlands; aboo@sint.azm.nl

Accepted 7 January 2002

\section{REFERENCES}

1 Boonen A, Chorus A, Miedema $\mathrm{H}$, van der Heijde D, van der Tempel $\mathrm{H}$ van der Linden Si. Employment, work disability and work days lost in patients with ankylosing spondylitis: a cross sectional study of Dutch patients. Ann Rheum Dis 2001;60:353-8.

2 Boonen A, Chorus A, Miedema H, van der Heijde D, Landewé R, Schouten $\mathrm{H}$, et al. Withdrawal from labour force due to work disability in patients with ankylosing spondylitis. Ann Rheum Dis 2001;60:1033-9.

Table 1 Annual withdrawal rate from the labour force due to official work disability in patients with ankylosing spondylitis for five classes of work and ratios when compared with the general population

\begin{tabular}{|c|c|c|c|c|c|c|}
\hline & \multicolumn{2}{|l|}{ Male patients } & \multicolumn{2}{|l|}{ Female patients } & \multicolumn{2}{|l|}{ All patients } \\
\hline & Withdrawal rate (\%) & SIR & Withdrawal rate (\%) & SIR $(95 \% \mathrm{CI})$ & Withdrawal rate $(\%)$ & $\operatorname{SIR}(95 \% \mathrm{CI})$ \\
\hline Manual job & 3.9 & 5.2 (3.6 to 6.4$)$ & 3.5 & $2.4(0.1$ to 4.7$)$ & 4.2 & 4.9 (3.5 to 5.9 ) \\
\hline Agriculture & 0 & - & 11.6 & 5.4 & 1.3 & 1.0 \\
\hline Industry & 4.1 & 5.3 & 3.2 & 2.2 & 4.3 & 4.9 \\
\hline Transport & 4.5 & 7.2 & 0 & - & 4.9 & 6.8 \\
\hline Non-manual job & 1.3 & 2.1 (1.3 to 2.8 ) & 2.8 & $2.2(1.3$ to 3.1$)$ & 2.0 & 2.2 (1.6 to 2.7$)$ \\
\hline Commercial & 1.0 & 1.9 & 3.5 & 3.0 & 1.9 & 2.3 \\
\hline Service & 1.4 & 2.1 & 2.7 & 2.1 & 2.1 & 2.1 \\
\hline All jobs & 2.3 & $3.4(2.6$ to 4.1$)$ & 2.9 & $2.2(1.4$ to 3.1$)$ & 2.7 & $3.0(2.5$ to 3.6$)$ \\
\hline
\end{tabular}

SIR, standardised incidence ratios of withdrawal. 


\title{
Breast implants and illness: a model of psychological illness
}

\author{
M Ahern, M Smith, H Chua, P Youssef
}

Ann Rheum Dis 2002;61:659

W e read with interest the hypothesis of Dush in the Annals of the Rheumatic Diseases ${ }^{1}$ and provide some evidence to support it. Dush suggested that many of the symptoms of women with silicone breast implants might be attributed to somatisation, stress, and mass somatisation. We recently reviewed 179 women with silicone breast implants who were involved in product liability and litigation.

Their ages ranged from 29 to 74 years (mean (SD) 46.8 (8.1)). The indications for surgery were cosmetic in $146(82 \%)$, followed by cancer in 17 (9\%), fibrocystic disease in $12(7 \%)$, and congenital hypoplasia in $4(2 \%)$ women. The most common symptoms were burning breast pain in $142(79 \%)$, chronic fatigue in $142(79 \%)$, arthralgia in $134(75 \%)$, sleep disturbance in 127 (71\%), cognitive dysfunction in $102(57 \%)$, sicca symptoms in 100 (56\%), night sweats in 97 (54\%), and myalgia in $91(51 \%)$. Findings on clinical examination were few, including chest wall abnormalities in 60 (34\%), tender trigger points in $31(17 \%)$, and carpal tunnel syndrome in 6 (3\%) women. Sixty five (36\%) women had radiological and/or surgical proof of implant leakage or rupture and 61 (34\%) had signs of implant contractures. We found no evidence of increased occurrence of any connective tissue disorder such as rheumatoid arthritis (RA), systemic lupus erythematosus (SLE), or Sjögren's syndrome.

The women were asked to complete two questionnaires and return them by mail: $(a)$ the General Health Questionnaire (GHQ), possibly the most widely used and extensively validated screening test for functional psychiatric illness-a score above 12 denoting significant psychiatric morbidity; $(b)$ the Speilberger State-Trait Anxiety Inventory (STAI). This comprises two self report scales for measuring two distinct anxiety concepts: (i) state anxiety (A state), which may vary over time and (ii) trait anxiety (A trait), a relatively enduring personality characteristic which does not tend to change much over time.

Of the 179 questionnaires sent, 117 were returned, giving a response rate of $(65 \%)$. The women had a mean (SD) score of 18.3 (8.2) on the GHQ; 75\% of women having scores above 12. Table 1 shows the means (SD) of the A state and A trait.
Patients with breast implant had significantly higher A state and A trait scores than female undergraduate students $(p<0.001)$ and medical/surgical inpatients $(p<0.001)$ and as much anxiety reaction as psychiatric patients with anxiety disorders.

Thus these women were found to have significant psychiatric morbidity and to show significant state and trait anxiety. The causes for these high anxiety levels may be related to the reasons these women sought breast implants-for example, poor self esteem, interpersonal and psychological problems. Possibly, these high anxiety levels are exacerbated by the litigation and media attention. The raised trait-anxiety levels maybe a risk factor for somatisation.

We attempted to reassure these women that there was no evidence of any underlying connective tissue disorder or systemic disease but could not allay their fears. Nevertheless, we identified the fact that these woman were distressed and required medical and psychological rehabilitation. Unfortunately, many of these women had been "dismissed" and their symptoms not taken seriously by their treating doctors because epidemiological research had not shown any association with recognisable systemic disease.

Because of the uncontrolled nature of our observations we can only propose a hypothesis for the causes of their symptoms. As rheumatologists encountering women with silicone breast implants, we need to reassure them that they are unlikely to have an underlying connective tissue disorder. We also must provide access to treatments that will alleviate their anxiety and distress, as suggested by Dush.

\section{Authors' affiliations}

M Ahern, M Smith, H Chua, P Youssef, Department of Rheumatology, Repatriation General Hospital, Adelaide, South Australia

Correspondence to: Professor M Ahern, Department of Rheumatology, Repatriation General Hospital, Flinders University of South Australia, Daws Road, Daw Park, South Australia 5041, Australia;

micharl.ahern@rgh.sa.gov.au

Accepted 18 December 2001

REFERENCE

1 Dush DM. Breast implants and illness: a model of psychological illness. Ann Rheum Dis 2001;60:653-7.

\begin{tabular}{lllll}
\hline Table 1 & A state and A trait scores, mean (SD) & & \\
\hline & $\begin{array}{l}\text { Silicone breast } \\
\text { implant }(\mathrm{n}=116)\end{array}$ & $\begin{array}{l}\text { Female } \\
\text { undergraduate } \\
\text { students }(\mathrm{n}=231)\end{array}$ & $\begin{array}{l}\text { Medical/surgical } \\
\text { patients }(\mathrm{n}=161)\end{array}$ & $\begin{array}{l}\text { Anxious psychiatric } \\
\text { patients }(\mathrm{n}=60)\end{array}$ \\
\hline A trait & $51.5(14.3)$ & $38.25(9.14)$ & $41.91(12.7)$ & $48.08(10.61)$ \\
A state & $53.1(13.6)$ & $35.16(9.3)$ & $43.28(13.8)$ & $49.02(11.6)$ \\
\hline
\end{tabular}




\title{
Fibromyalgia in patients with rheumatoid arthritis is associated with higher scores of disability
}

\author{
A Naranjo, S Ojeda, F Francisco, C Erausquin, I Rúa-Figueroa, C Rodríguez-Lozano
}

Ann Rheum Dis 2002;61:660-661

$R^{\prime}$ heumatoid arthritis (RA) is a chronic polyarticular disease characterised by pain in peripheral joints accompanied by swelling, stiffness, and functional impairment. In some cases it is associated with fibromyalgia (FM), a syndrome defined by chronic, widespread pain, asthenia, and sleep disorders. When a patient has both RA and FM, determining the degree of RA activity may be difficult, because these patients typically have higher scores for pain and disability.

This study aimed at evaluating whether there were differences in functional disability, extra-articular manifestations, and use of disease modifying antirheumatic drugs (DMARDs), between patients with RA with and without FM.

\section{PATIENTS AND METHODS}

A cross sectional study was conducted with 386 patients with RA, 94 men and 292 women, with a mean age of 53 years. All the patients met the criteria of the American College of Rheumatology (ACR) for the diagnosis of the disease. ${ }^{1}$ The mean duration of the disease was nine years. All the patients received treatment in a hospital outpatient clinic and were included in a database between 1991 and 2000. To diagnose FM, ACR criteria had to be fulfilled on at least two consecutive visits. ${ }^{2}$ The following assessment was made in all patients participating in the study: a clinical history, evaluation of functional status using the Health Assessment Questionnaire (HAQ), ${ }^{3}$ conventional laboratory measurements, and evaluation of the rheumatoid factor. In addition to these assessments, extra-articular manifestations were diagnosed. Secondary Sjögren's syndrome was diagnosed when, in addition to subjective xerophthalmia and xerostomia, Schirmer's test or the rose bengal staining were pathological. ${ }^{4}$ The number of previous DMARDs was counted, independently of whether the patient received a single drug or a combination.

Contingency tables were used to compare the frequency of categorical variables among the different groups. To compare numerical variables we used Student's $t$ test when the data followed a normal distribution and the equivalent Wilcoxon non-parametric test when they did not.

\section{RESULTS}

Of the total, 57 (14.8\%) patients fulfilled FM criteria. No differences were found in age or disease duration between patients with RA without FM (RA group) and patients with RA and FM (RA-FM group) (table 1). In the RA-FM group there was a higher percentage of women $(p=0.03)$; HAQ scores $(p=0.002)$ were also higher. The incidence of extra-articular manifestations such as serositis, pneumonitis, or Sjögren's syndrome was similar in both groups. Rheumatoid nodules and the rheumatoid factor were more common in the RA group, although differences were not significant. The RA-FM group had received a greater number of DMARDs $(p=0.04)$.

\section{DISCUSSION}

The results of this study indicate that patients with RA who also have FM are more often women, have higher disability scores, and receive DMARDs more frequently.

Wolfe et al studied 242 patients with RA and 38 who had FM occurring in association with RA. The RA-FM group had more abnormal measures of function, pain, disease activity, and psychological status, but the disease severity in RA-FM and RA was similar. ${ }^{5}$ In patients with RA, FM tender points have been found to correlate mainly with daily stress and with higher joint tenderness count scores, indicating that patients with RA and FM have a lower pain threshold. ${ }^{6}{ }^{7}$ Patients with RA and depression often perform fewer daily life activities. ${ }^{8}$

In summary, FM is found to be associated in one of seven patients with RA; the presence of FM may constitute a marker of a worse prognosis for subjective functional disability.

\section{Authors' affiliations}

A Naranjo, S Ojeda, F Francisco, C Erausquin, I Rúa-Figueroa, C Rodríguez-Lozano, Rheumatology Service, Hospital de Gran Canaria Dr Negrín, Las Palmas de Gran Canaria, Spain

Correspondence to: Dr A Naranjo, Rheumatology Service, Hospital de Gran Canaria Dr Negrín, C/ Barranco de la Ballena s/n 35020, Las Palmas de Gran Canaria, Spain; anarher@gobiernodecanarias.org

Accepted 11 December 2001

Table 1 Comparison of patients with rheumatoid arthritis (RA) and rheumatoid arthritis and fibromyalgia (RA-FM)

\begin{tabular}{llll}
\hline & RA-FM & RA & p Value \\
\hline Number of patients & 57 & 329 & \\
Women (No (\%)) & $50(88)$ & $242(74)$ & 0.03 \\
Mean (SD) age (years) & $52(9.6)$ & $53(15)$ & 0.42 \\
Duration of RA disease (SD), years & $8(8)$ & $9(9)$ & 0.35 \\
HAQ (mean (SD)) & $1.62(0.70)$ & $1.21(0.77)$ & 0.002 \\
Patients with rheumatoid factor (No (\%)) & $37(65)$ & $247(75)$ & 0.13 \\
Extra-articular manifestations & $10(18)$ & $82(25)$ & 0.36 \\
$\quad$ Rheumatoid nodules (No (\%)) & $15(26)$ & $80(24)$ & 0.97 \\
$\quad$ Secondary Siögren's syndrome (No (\%)) & $3(5)$ & $12(4)$ & 0.99 \\
$\quad$ Serositis (No (\%)) & 0 & $17(5)$ & 0.04 \\
$\quad$ Interstitial lung disease (No (\%)) & $2.64(1.6)$ & $2.17(1.5)$ & 0.04 \\
\hline
\end{tabular}




\section{REFERENCES}

1 Arnett FC, Edworthy SM, Bloch DA, McShane DJ, Fries JF, Cooper NS, et al. The American Rheumatism Association 1987 revised criteria for the classification of rheumatoid arthritis. Arthritis Rheum 1988;31:315-24

2 Wolfe F, Smythe HA, Yunus MB, Bennett RM, Bombardier C, Goldenberg DL, et al. The American College of Rheumatology 1990 criteria for the classification of fibromyalgia. Report of the multicenter criteria committee. Arthritis Rheum 1990;33:160-72.

3 Esteve-Vives J, Batlle-Gualda E, Reig A. Spanish version of the Health Assessment Questionnaire: reliability, validity and transcultural equivalency. (Grupo para la adaptación del $\mathrm{HAQ}$ a la población española.) J Rheumatol 1993;20:2116-22.
4 Vitali C Bombardieri S, Moutsopoulos HM Balestrieri G, Bencivelli W Bernstein RM, et al. Preliminary criteria for the classification of Sjögren's syndrome. Results of a prospective concerted action supported by the European Community. Arthritis Rheum 1993;36:340-7

5 Wolfe F, Cathey MA, Kleinheksel SM. Fibrositis (fibromyalgia) in rheumatoid arthritis. J Rheumatol 1984;11:814-18.

6 Urrows S, Affleck G, Tennen H, Higgins P. Unique clinical and psychological correlates of fibromyalgia tender points and joint psychological correlates of fibromyalgia tender points and joint

7 Konttinen YT, Honkanen VE, Gronblad M, Keinonen M, Santavirta N Santavirta $S$. The relation of extraarticular tenderness to inflammatory joint disease and personality in patients with rheumatoid arthritis. J Rheumatol 1992;19:851-5.

8 Katz PP, Yelin EH. Life activities of persons with rheumatoid arthritis with and without depressive symptoms. Arthritis Care Res 1991;7:69-77.

\section{Shingles following infliximab infusion}

\section{C Baumgart, A U Dignass}

nfliximab is a chimeric IgGl $\kappa$ monoclonal antibody that

binds specifically to human tumour necrosis factor alpha

$(\mathrm{TNF} \alpha)$. Infliximab, in combination with methotrexate, is approved for reducing signs and symptoms and inhibiting the progression of structural damage in patients with moderately to severely active rheumatoid arthritis who have had an inadequate response to methotrexate. It will also reduce the signs and symptoms of Crohn's disease in patients with moderately to severely active Crohn's disease who have had an inadequate response to conventional treatment and will reduce the number of draining enterocutaneous fistulas in patients with fistulising Crohn's disease. ${ }^{12}$ Owing to its mechanism of action infliximab can lead to a number of complications.

\section{CASE REPORT}

Here we report a case of shingles, an infectious complication, currently not included in the product labelling.

A 45 year old man with steroid dependent Crohn's disease presented to the outpatient clinic with an acute flare up. At that time he had already been receiving $150 \mathrm{mg}$ of azathioprine and $1000 \mathrm{mg}$ mesalamine by mouth three times a day for about 17 months. Prednisolone had been tapered to $5 \mathrm{mg}$ a day. High resolution intestinal ultrasound showed a subtotal small bowel stenosis. Power Doppler demonstrated mucosal hyperaemia, suggesting an inflammatory process.

It was therefore decided to switch his treatment to infliximab. His condition slightly improved, but after the third course of $5 \mathrm{mg} / \mathrm{kg}$ bodyweight infliximab he developed a painful, pustular skin rash on the left side of his chest involving several dermatomas. Varicella zoster IgM titres were raised, confirming an acute shingles infection. He was treated intravenously with $5 \mathrm{mg} / \mathrm{kg}$ bodyweight acyclovir every eight hours for seven days. He recovered and was later referred for surgery to resect the inflamed segment.

\section{DISCUSSION}

Adult varicella can be a severe illness complicated by pneumonia, encephalitis, hepatitis, thrombocytopenia, and prolonged fever. ${ }^{3}$ Blood levels of TNF $\alpha$ have been shown to be raised in patients with acute varicella infection. ${ }^{4}$ In vitro studies have shown that replication of varicella zoster virus and varicella zoster virus antigen expression are inhibited by TNF $\alpha$ and that this antiviral activity can be completely blocked by monoclonal antibodies against TNF $\alpha .^{5}$

The use of monoclonal antibodies against TNF $\alpha$ in patients with inflammatory bowel disease increases the risk of viral infections by inhibiting an adequate TNF $\alpha$ response. Doctors should be cautious when prescribing infliximab for patients who are already receiving immunosuppressant drugs. We suggest that varicella zoster virus infection should be included as an infectious complication in the drug labelling.

\section{Authors' affiliations}

D C Baumgart, A U Dignass, Universitätsklinikum Charité, Campus Virchow-Klinikum, Medizinische Fakultät der Humboldt-Universität zu Berlin, Medizinische Klinik mit Schwerpunkt Hepatologie und Gastroenterologie, D-13344 Berlin, Germany

Correspondence to: Dr D C Baumgart, Charité-Campus Virchow-Klinikum, Humboldt-Universität zu Berlin, Hepatologie und Gastroenterologie, D-13344 Berlin, Germany; daniel.baumgart@charite.de

Accepted 3 January 2002

\section{REFERENCES}

1 Lipsky PE, van der Heijde DM, St Clair EW, Furst DE, Breedveld FC Kalden JR, et al. Infliximab and methotrexate in the treatment of rheumatoid arthritis. Anti-tumor necrosis factor trial in rheumatoid arthritis with concomitant therapy study group. N Engl J Med 2000;343:1594602

2 Targan SR, Hanauer SB, van Deventer SJ, Mayer L, Present DH, Braakman T, et al. A short-term study of chimeric monoclonal antibody cA2 to tumor necrosis factor alpha for Crohn's disease. Crohn's disease cA2 Study Group. N Engl J Med 1997;337:1029-35

3 Liesegang TJ. Varicella zoster viral disease. Mayo Clin Proc 1999;74:983-98

4 Wallace MR, Woelfl I, Bowler WA, Olson PE, Murray NB, Brodine SK et al. Tumor necrosis factor, interleukin-2, and interferon-gamma in adult varicella. J Med Virol 1994;43:69-71.

5 Ito $M$, Nakano T, Kamiya T, Kitamura K, Ihara T, Kamiya H, et al. Effects of tumor necrosis factor alpha on replication of varicella-zoster virus. Antiviral Res 1991;15:183-92. 


\title{
Self limiting lupus-like symptoms in patients with parvovirus B19 infection
}

\author{
E Tóvári, I Mezey, K Hedman, L Czirják
}

$\mathrm{P}$ arvovirus B19 causes polyarthritis in adults. ${ }^{1}$ Several observers have noted a lupus-like syndrome ${ }^{23}$ and production of autoantibodies associated with this infection. ${ }^{4}$ We describe here two white patients with acute parvovirus B19 infection and a transient lupus-like syndrome.

\section{CASE REPORTS}

\section{Case 1}

A 41 year old woman had a transient polyarthritis of the metacarpophalangeal (MCP) and proximal interphalangeal (PIP) joints after her first delivery at the age of 30, and she developed photosensitivity, and reported dryness of the eyes for some years.

In 1998 she had an influenza-like illness with polyarthralgia, myalgia, and fever. She also had a massive UV light exposure with tanning. Two days later she developed polyarthritis of the wrists, MCP, and PIP joints. Her 4 year old child had a fever and facial skin rash just before her disease.

One week after the start of her polyarthritis she had a normal blood count, erythrocyte sedimentation rate (ESR), rheumatoid factor, complement, immunoglobulin levels, urine analysis, liver enzymes, creatinine kinase, and slightly raised ( $15 \mathrm{mg} / \mathrm{l}) \mathrm{C}$ reactive protein (CRP). Anti-dsDNA, anticardiolipin, IgG and IgM were increased, and anti-SS-A, anti-SS-B antibodies were also detected by enzyme linked immunosorbent assay (ELISA). An antinuclear antibody (ANA) test was negative, with an anti-cytoskeletal staining on HEp-2 cells. Both IgM and IgG antibodies to human parvovirus B19 were positive, and parvovirus DNA was detected by nested polymerase chain reaction (PCR) in serum.

After eight weeks the autoantibody tests became negative, and her symptoms completely resolved. At two years follow up she remained asymptomatic, and the parvovirus PCR was negative.

\section{Case 2}

A 34 year old woman was examined in June 1998 with an acute painful occipital lymph node and polyarthritis in the
MCP and PIP joints. She had had photosensitivity from the age of 10. Two weeks before symptoms, her child had a rash and flu-like illness, and in the meantime she was exposed to UV light with tanning.

Urine analysis, blood count, liver enzymes were normal, but the ESR and CRP were slightly raised $(22 \mathrm{~mm} / \mathrm{lst} \mathrm{h}$, and 11 $\mathrm{mg} / \mathrm{l}$, respectively). No rheumatoid factor was detected. Anti-dsDNA and anti-Sm autoantibody were positive by ELISA. An ANA test was negative on HEp-2 cells, with an atypical cytoplasmic staining. IgM and IgG antibodies to human parvovirus B19 were present, and parvovirus DNA was detected by PCR in serum. The patient was three weeks' pregnant but she decided to terminate the pregnancy. After 10 weeks the autoantibody ELISA became negative, but the ANA test became positive with homogeneous staining pattern. Apart from periodic myalgia and arthralgia the patient remained without symptoms for two years. The diagnosis may be systemic lupus erythematosus (SLE) in view of the photosensitivity, polyarthritis, ANA, and anti-dsDNA positivity. At 500 days after the onset PCR was positive in serum.

\section{DISCUSSION}

After the infection four criteria of SLE were fulfilled in case 2, and case 1 was compatible with the diagnosis of undifferentiated connective tissue disease. ${ }^{5}$ The autoimmune process was self limited in both patients.

The patients' children had symptoms of erythema infectiosum, and the mothers were examined for parvovirus B19. They were IgM and IgG positive (table 1). The VPl-IgG avidity $^{6}$ and VP2-IgG epitope type specificity ${ }^{7}$ results (table 1) confirmed acute B19 infection in our patients. Nested PCR was performed on the patients' sera. ${ }^{8}$ Both patients were PCR positive in the acute phase (table 1). In immunocompetent patients PCR may remain positive for four months, but more prolonged persistence in healthy subjects is unusual. Parvovirus DNA was not detectable in the first patient after 400 days, but in patient 2 the blood sample taken at 500 days was positive.

\begin{tabular}{|c|c|c|c|c|c|c|}
\hline & $\begin{array}{l}\text { Days after onset } \\
\text { of polyarthritis }\end{array}$ & VP2-IgM EIA & VP2-lgG EIA & VP2-ETS ratio & $\begin{array}{l}\text { VP1-IgG } \\
\text { avidity (\%) }\end{array}$ & PCR \\
\hline \multirow[t]{3}{*}{ Case 1} & 7 & Pos & Pos & 0.38 & 6.3 & + \\
\hline & 20 & ND & Pos & 0.41 & 6.6 & + \\
\hline & 400 & $\mathrm{Neg}$ & Pos & 232.57 & 52.8 & - \\
\hline \multirow[t]{6}{*}{ Case 2} & 4 & Pos & Pos & 0.28 & - & + \\
\hline & 24 & ND & Pos & 0.49 & 6.2 & ND \\
\hline & 47 & Pos & Pos & 0.81 & 11.8 & + \\
\hline & 110 & $\mathrm{Neg}$ & Pos & 4.98 & 24.7 & + \\
\hline & 144 & - & Pos & 13.42 & 26.5 & + \\
\hline & 500 & ND & ND & ND & ND & + \\
\hline \multicolumn{7}{|c|}{$\begin{array}{l}\text { VP2, major capsid protein; VP1, minor capsid protein; ETS, epitope type-specific lgG; pos, positive; neg, } \\
\text { negative; ND, not determined. } \\
\text { Zone of acute infection in VP2/ETS ratio 0-10; zone of past immunity }>10 \text {. } \\
\text { Zone of acute infection in VP1 lgG avidity } 0-15 \% \text {; borderline zone } 16-25 \% \text {, zone of past immunity: }>25 \% \\
\text { Signs of acute parvovirus infection are shown in bold. }\end{array}$} \\
\hline
\end{tabular}




\begin{tabular}{|c|c|c|c|c|c|c|c|c|c|}
\hline Patient & HLA-A & HLA-B & HLA-C & HLA-DR & DRB1 & DRw & $\mathrm{DQ}$ & DQA1 & DQB1 \\
\hline 1 & 1 & $\begin{array}{r}8(\mathrm{Bw} 6) \\
37(\mathrm{Bw} 4)\end{array}$ & 7 & $\begin{array}{r}2 \\
13\end{array}$ & $\begin{array}{l}1501 \\
1302\end{array}$ & $\begin{array}{l}51 \\
52\end{array}$ & $\begin{array}{l}6 \\
6\end{array}$ & $\begin{array}{l}0101-05 \\
0101-05\end{array}$ & $\begin{array}{l}0602 / 10-11 / 13 \\
0603-09 / 12 / 14\end{array}$ \\
\hline 2 & $\begin{array}{l}2 \\
9\end{array}$ & $\begin{array}{r}18 \text { (Bw6) } \\
7(\mathrm{Bw} 6)\end{array}$ & $\begin{array}{l}2 \\
7\end{array}$ & $\begin{array}{r}2 \\
11\end{array}$ & $\begin{array}{l}1501 \\
1104\end{array}$ & $\begin{array}{l}51 \\
52\end{array}$ & $\begin{array}{l}6 \\
7\end{array}$ & $\begin{array}{l}0101-05 \\
0501-04\end{array}$ & $\begin{array}{l}0602 / 10-11 / 13 \\
0301\end{array}$ \\
\hline
\end{tabular}

HLA haplotypes, which have been described as associated with SLE are shown in bold.

At the time of the infection other provoking factors for SLE could also be identified. The second patient had an early phase pregnancy. Although the patients had earlier had photosensitivity, they were tanning during the initial period of infection. The typical rash of parvovirus infection, like the skin manifestations of SLE, can be provoked by UV light. Possibly, the virus and the UV light had additional effects on the autoimmune process.

Typing for HLA-A, B, C, and DR, DQ showed common alleles. They had DR2 (DRB1*1501) and DQ6 (DQB1*0602) with the same subtypes (table 2 ). Four HLA alleles of the patients have been previously described as associated with SLE. ${ }^{9}$

In conclusion, we have found several common provoking factors of the autoimmune process in our cases. The patients had a genetic predisposition to lupus and also signs of autoimmune diseases in the past. They had also been exposed to UV light and pregnancy, which are known provoking factors for SLE. Furthermore, parvovirus infection seemed to be also a provoking factor for the development of SLE and lupus-like disease, although the symptoms of connective tissue diseases were transient.

Authors' affiliations

E Tóvári, L Czirják, 2nd Department of Internal Medicine, University of

Pécs, Medical Faculty, Pécs, Hungary

I Mezey, Bela Johan' National Centre for Epidemiology, Division of

Virology, Budapest, Hungary

K Hedman, Department of Virology, Haartman Institute and $\mathrm{HUCH}$

Diagnostic, University of Helsinki, Finland
Correspondence to: Professor L Cziriák, University of Pécs, Medical Faculty Nephrology Centre and 2nd Department of Internal Medicine, Clinical Immunology Unit, H-7624 Pécs, Pacsirta u. 1., Hungary; laszlo.czirjak@aok.pte.hu

Accepted 14 December 2001

\section{REFERENCES}

1 White DG, Woolf AD, Mortimer PP, Cohen BJ, Blake DR, Bacon PA. Human parvovirus arthropathy. Lancet 1985;i:419-21.

2 Gran JT, Johnsen V, Myklebust G, Nordbo SA. The variable clinical picture of arthritis induced by human parvovirus B 19. Report of seven adult cases and review of the literature. Scand J Rheumatol 1995:24:174-9.

3 Nesher G, Osborn TG, Moore TL. Parvovirus infection mimicking systemic lupus erythematosus. Semin Arthritis Rheum 1995;24:297-303.

4 Loizou S, Cazabon JK, Walport M, Tait D, So AK. Similarities of specificity and cofactor dependence in serum antiphospholipid antibodies from patients with human parvovirus B 19 infection and from those with systemic lupus erythematosus. Arthritis Rheum 1997;40:103-8.

5 Calvo Alen J, Alarcón GS, Burgard SL, Burst N, Bartolucci AA, Williams $\mathrm{HJ}$. Systemic lupus erythematosus: predictors of its occurrence among a cohort of patients with early undifferentiated connective tissue disease: multivariate analyses and identification of risk factors. J Rheumatol 1996;23:469-75

6 Söderlund M, Brown CS, Cohen BJ, Hedman K. Accurate serodiagnosis of B19 parvovirus infections by measurement of IgG avidity. J Infect Dis 1995;171:710-13.

7 Kaikkonen L, Lankinen H, Harjunpää I, et al. Acute-phase-specific heptapeptide epitope for diagnosis of parvovirus B 19 infection. J Clin Microbiol 1999;37:3952-6.

8 Hornsleth A, Carlsen KM, Christensen LS, Gundestrup M, Heegaard ED, Myhre J. Estimation of serum concentration of parvovirus B-19 DNA by PCR in patients with chronic anaemia. Res Virol 1994;145:379-86.

9 Arnett FC Jr. The genetics of human lupus. In: Wallace DJ, Hahn BH, ed. Dubois' lupus erythematosus. Baltimore: William and Wilkins, 1997:77-117.

\section{Dermatomyositis in a patient with adenocarcinoma of the gall bladder}

\section{G Yiannopoulos, P Ravazoula, N Meimaris, M Stavropoulos, A P Andonopoulos}

A case of dermatomyositis in an elderly woman, found to have gall bladder adenocarcinoma, is presented. As far as we know this is the first report of an association between the myopathy and this specific malignancy.

\section{CASE REPORT}

A 75 year old white woman was admitted to our department, with a seven month history of proximal muscle weakness, dysphagia, dysphonia, facial erythema, and oedema of the eyelids. Atypical dyspeptic symptoms had been present for the same time period. At that time, an abdominal ultrasound showed, besides multiple gall stones, increased echogenicity of the gall bladder content. Simultaneous routine laboratory tests were normal, except for a minimal increase of serum aspartate aminotransferase (AST) and alanine aminotransferase (ALT) and a creatine kinase (CK) value of $350 \mathrm{IU} / \mathrm{ml}$ (upper normal 190). Apparently, that had gone unnoticed, until her admission.

On physical examination, she was found to be a relatively obese elderly woman, in no distress, with normal vital signs. A "heliotrope" rash was present in her eyelids, and Gottron's papules were noticed on the dorsal surface of her metacarpophalangeal and proximal interphalangeal joints bilaterally. Proximal muscle weakness of the neck, shoulder, and pelvic girdles was prominent. The rest of the physical examination was unremarkable.

Routine laboratory tests, including CK, were normal, except for a mild increase of AST and lactate dehydrogenase (LDH). 


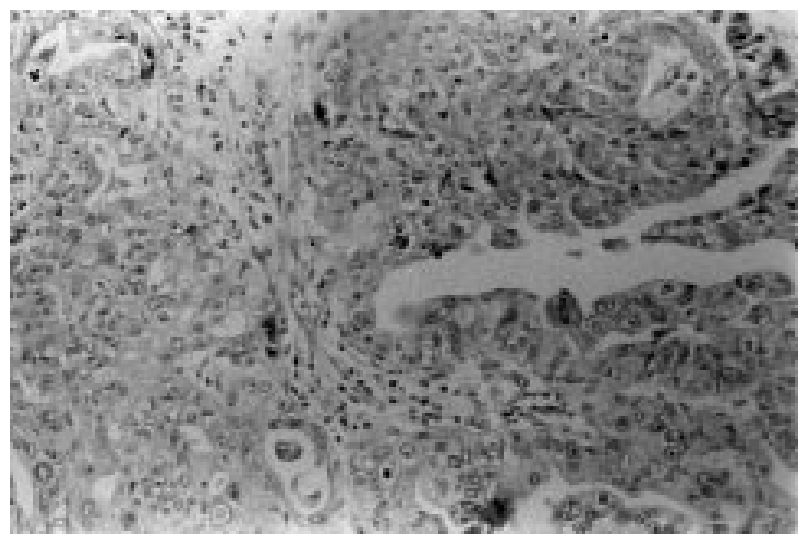

Figure 1 Histology of the surgical specimen of the patient (haematoxylin and eosin, $\times 200$ ), showing moderately differentiated adenocarcinoma of the gall bladder.

Thyroid function was within the normal range. Serum antinuclear antibodies were positive at a titre of $1 / 160$ with a fine speckled pattern. The rest of the serological profile was normal.

A chest $x$ ray examination was unremarkable. Gastroscopy showed mild gastritis. Abdominal ultrasound was essentially the same as the one performed seven months previously. An electromyogram of the proximal muscles disclosed decreased amplitude and duration of motor unit action potentials and an increased proportion of polyphasic potentials, increased insertional activity and fibrillation. A deltoid muscle biopsy showed typical findings of dermatomyositis.

The patient was treated with methylprednisolone $48 \mathrm{mg}$ daily, and asked to be discharged. We continued the investigations to detect a possible underlying malignancy, during a close follow up. She improved clinically with methylprednisolone, and the steroid dose was gradually tapered. Meanwhile, a bone scan and a mammogram were read as normal. However, an abdominal computed tomography (CT) scan showed thickening of the gall bladder wall and enlargement of the lymph nodes around the portal vein and hepatic artery.

Two months after her initial presentation to us, she was admitted to the surgical department for exploratory laparotomy; her muscle strength had improved, and she had no rash or jaundice, while taking methylprednisolone 16 $\mathrm{mg} /$ day. At that time, her alkaline phosphatase and $\gamma$-glutamyltransferase $(\gamma \mathrm{GT})$ were markedly raised, by three and eight times normal, respectively. At surgery, cancer of the gall bladder was found, with intrahepatic metastases and involvement of the lymph nodes of the hepatoduodenal ligament; a cholecystectomy was performed. The specimen disclosed a moderately differentiated adenocarcinoma, affecting most of the gall bladder wall, and at its full thickness expanding to the surrounding fatty tissue (fig l).

Ten weeks after discharge, she was readmitted to the medical service, severely debilitated, with profound muscle weakness and jaundice, nodular hepatomegaly, and oedema. Laboratory tests showed mild anaemia, markedly raised alkaline phosphatase, $\gamma \mathrm{GT}$, and $\mathrm{LDH}$, bilirubin of $548 \mu \mathrm{mol} / \mathrm{l}$, but normal CK. The patient's already serious condition deteriorated further, she developed a left lower lobe pneumonia and died 10 days after her admission.

\section{DISCUSSION}

A number of studies have suggested an association between inflammatory myopathy and malignancy, which seems stronger with dermatomyositis and weaker with

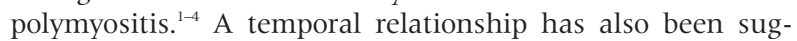
gested, with the diagnosis of malignancy coinciding with, pre- ceding, or following that of myositis, usually within two years, ${ }^{235}$ although longer periods of surveillance have been recommended. ${ }^{4}$

With the exception of gastric and ovarian carcinoma, which seem to more commonly underlie myositis, the spectrum of the various kinds of cancer in patients with inflammatory myopathy is similar to that in the general population. ${ }^{3}$ However, an association of dermatomyositis with tumours of the biliary tract is extremely rare. According to the available published reports, there are only three cases of dermatomyositis in patients with cholangiocarcinoma (two of them in nonEnglish literature), ${ }^{6-8}$ and in no patient with gall bladder carcinoma has inflammatory myopathy been described. Furthermore, in a recent excellent population based study of 618 patients with dermatomyositis, of whom 198 were found to have cancer, no gall bladder carcinoma was identified. Therefore, our patient seems to be the first report of an association between dermatomyositis and adenocarcinoma of the gall bladder. Her myopathy responded initially to steroids, despite the advanced stage of her cancer, in accordance with some observations, suggesting occasionally independent courses of dermatomyositis and malignancy. ${ }^{10}$

In conclusion, carcinoma of the gall bladder should be added to the list of malignancies, which dermatomyositis can complicate, as a paraneoplastic process.

\section{Authors' affiliations}

G Yiannopoulos, N Meimaris, A P Andonopoulos, Division of Rheumatology, Department of Medicine, University of Patras School of Medicine, Patras, Greece

P Ravazoula, Department of Pathology, University of Patras School of Medicine

M Stavropoulos, Department of Surgery, University of Patras School of Medicine

Correspondence to: Professor A P Andonopoulos, Division of Rheumatology, Department of Medicine, University of Patras School of Medicine, 26500 Rio, Patras, Greece; andandon@med.upatras.gr

Accepted 28 January 2002

D van der Heijde, Limburg University Centre, Diepenbeek, Belgium H Miedema, Netherlands Expert Centre for Workrelated Musculoskeleta Disorders, University Hospital Dijkzigt and Erasmus University Rotterdam, The Netherlands

H van der Tempel, Maasland Ziekenhuis Sittard, The Netherlands

Correspondence to: $\mathrm{Dr}$ A Boonen, Department of Internal Medicine, Division of Rheumatology, University Hospital Maastricht, PO Box 5800 , 6202 AZ Maastricht, The Netherlands; aboo@sint.azm.nl

Accepted 7 January 2002

\section{REFERENCES}

1 Barnes BE. Dermatomyositis and malignancy. Ann Intern Med 1976:84:68-76.

2 Manchul LA, Jin A, Pritchard KI, Tenenbaum J, Boyd NF, Lee P, et al. The frequency of malignant neoplasms in patients with polymyositis-dermatomyositis. Arch Intern Med 1985;145:1835-9.

3 Sigurgeirsson B, Lindelof B, Edhag $O$, Allander E. Risk of cancer in patients with dermatomyositis or polymyositis. N Engl J Med 1992;326:363-7

4 Richardson JB, Callen JP. Dermatomyositis and malignancy. Med Clin North Am 1989:73:1211-20.

5 Tymms KE, Webb J. Dermatomyositis and other connective tissue diseases: a review of 105 cases. J Rheumatol 1985;12:1140-8.

6 Rorive A, Fraipont V, Quatresooz P, Cataldo D, Dubois B, Fillet G. Clinical case of the month. A case of acute rhabdomyolysis. Rev Med Liege 1999;54:143-8.

7 Horie Y, Yamada M, Nakai K, Kawasaki H, Hirayama C, Matsui K, et al. Combined hepatocellular-cholangiocarcinoma associated with dermatomyositis. J Gastroenterol Hepatol 1989;4:101-4.

8 Llinares Mondejar P, Amador Barciela L, Arnal Monreal F, Beraza Milicua A, Toro Santos M, del Rio Vazquez A. Associated dermatomyositis and cholangiocarcinoma. Rev Clin Esp 1982; 164:335-7

9 Hill CL, Zhang Y, Sigurgeirsson B, Pukkala E, Mellemkjaer L, Airio A, et al. Frequency of specific cancer types in dermatomyositis and polymyositis: a population-based study. Lancet 2001;357:96-100.

10 Yazici Y, Kagen LJ. The association of malignancy with myositis. Curr Opin Rheumatol 2000;12:498-500. 


\title{
Coincidence of asymptomatic avascular necrosis and fracture of the femoral neck: a rare combination of glucocorticoid induced side effects
}

\author{
K Loddenkemper, C Perka, G-R Burmester, F Buttgereit
}

Ann Rheum Dis 2002;61:665-666

G lucocorticoids have profound anti-inflammatory and immunosuppressive actions when used therapeutically. Unfortunately, these drugs have adverse effects-for example, on bone metabolism. Osteoporosis is well known to be a common side effect, whereas a glucocorticoid associated avascular osteonecrosis is rarely diagnosed. However, as far as we know, the coincidence of manifest osteoporosis with fracture and avascular osteonecrosis in the same area is unique.

\section{CASE REPORT}

We present the case of a 47 year old postmenopausal woman who had had mixed connective tissue disease (MCTD) for more than 20 years. The MCTD was complicated by progressive vasculitis, and had required immunosuppressive treatment with prednisolone (maximum dose $500 \mathrm{mg} /$ day (pulse therapy; average dose $15 \mathrm{mg} /$ day) for 20 years and azathioprine ( $75 \mathrm{mg} /$ day). In 1995, she complained for the first time of severe back pain and noticed a height loss of $10 \mathrm{~cm}$ within two years. There was no history of previous fractures.

Glucocorticoid induced osteoporosis was suspected. Indeed, bone densitometry (DXA-LUNAR) showed decreased bone mineral density (BMD) of the lumbar spine (L2-4) and left femoral neck (table 1). An $x$ ray examination demonstrated osteoporotic changes-for example, end plate fractures, osteopenia. Treatment with fluorides, vitamin $\mathrm{D}$, and calcium was started. One year later the BMD of the lumbar spine had increased, whereas the BMD of the femoral neck and back pain remained unchanged. Consequently, the treatment was changed to bisphosphonates (alendronate) supplemented by calcium and vitamin D. Another year later her back pain was reduced. The BMD of lumbar spine had become stable while decreasing by $30 \%$ at the femoral neck (table 1 ). No evidence of fluorosis, secondary hyperparathyroidism, or abnormal vitamin D metabolism was found.

Shortly after this visit the patient was admitted to hospital for alprostadil treatment of her Raynaud's phenomenon associated with the MCTD. She complained of sudden severe pain in her left hip during a forest walk. Surprisingly, an $x$ ray examination showed left femoral head fracture and avascular necrosis (early radiological Ficat stage IV) (fig 1). ${ }^{1}$ After successful hip replacement, the patient was able to walk without pain.

Table 1 Bone mineral density of lumbar spine and femoral neck over the course of three years

\begin{tabular}{lccc}
\hline & 1995 & 1996 & 1997 \\
\hline Lumbar spine $\left(\mathrm{mg} / \mathrm{cm}^{2}\right)$ & 0.800 & 0.875 & 0.874 \\
Lumbar spine $(t \mathrm{score})$ & -3.33 & -2.71 & -2.83 \\
Femoral neck $\left(\mathrm{mg} / \mathrm{cm}^{2}\right)$ & 0.538 & 0.549 & 0.381 \\
Femoral neck $(t$ score) & -3.68 & -3.68 & -4.99 \\
\hline
\end{tabular}

\section{DISCUSSION}

This patient with MCTD demonstrates typical side effects of long term glucocorticoid treatment, but several points are of particular interest:

(1) Osteoporosis treatment had been started at a time when the BMD was already decreased. Other risk factors were early menopause without hormone replacement therapy and inflammatory rheumatic disease (cytokines can affect bone turnover). Official guidelines for the prevention of glucocorticoid induced osteoporosis were published by the American

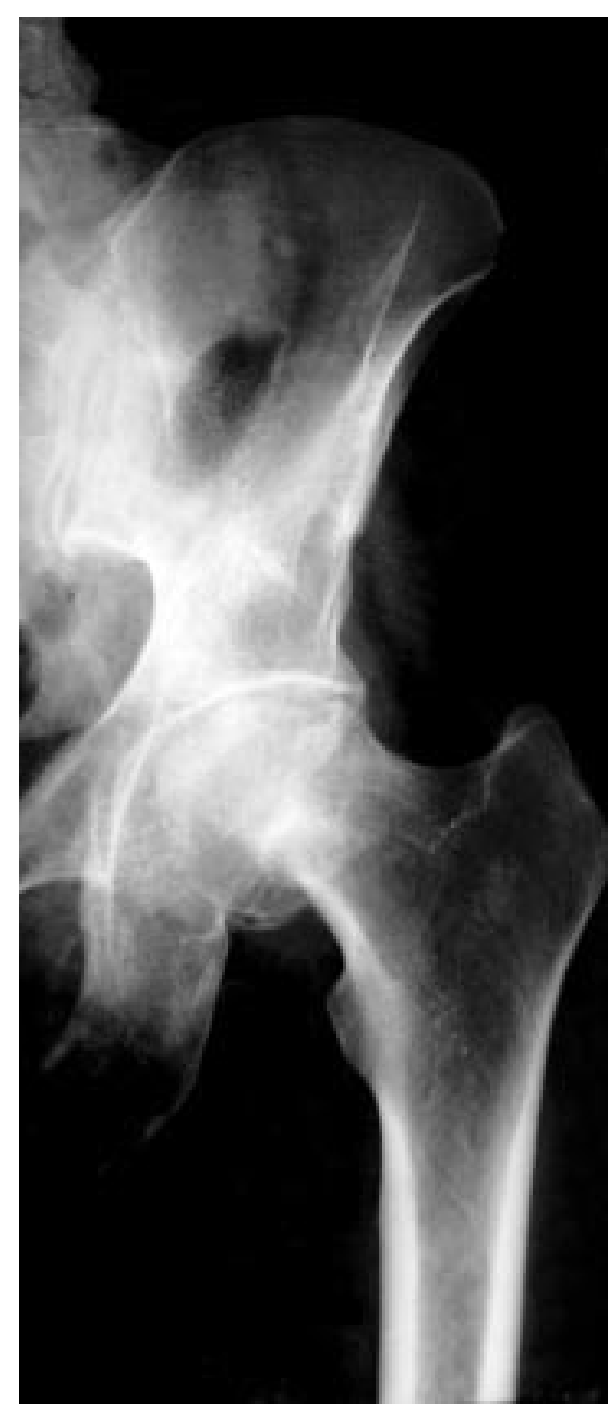

Figure 1 An $x$ ray image of the left hip showing femur head necrosis (early radiological Ficat stage IV) and fracture of the left femoral neck. 
College of Rheumatology in $1996 .^{2}$ Today it is clear that early prophylaxis can prevent manifest osteoporosis. Potent drugs for the prevention and treatment of osteoporosis are bisphosphonates and substitution of calcium and vitamin D. ${ }^{3}$

(2) Another important aspect is osteoporosis with intercurrent avascular osteonecrosis of the left femoral head. The absence of pain in this condition is uncommon. To the best of our knowledge, unilateral osteonecrosis of the hip at an advanced stage without pain has not been previously reported. Only early stage forms or one hip without pain in bilateral osteonecrosis have been described. ${ }^{45}$ Avascular necrosis is not a specific disease entity. Predisposing factors are trauma, glucocorticoids, alcohol abuse, and connective tissue disorders. It may also be idiopathic. ${ }^{6}$ Avascular necrosis is a rare side effect of glucocorticoid treatment and is normally painful. In autoimmune diseases a correlation has been shown between glucocorticoids and bone death, which appears to be due to blood stasis and ischaemia in the trabecular bone. Theories of thrombotic formation or fat embolism have proved to be invalid. ${ }^{7}$ A further suspected mechanism could be the increase of osteocyte apoptosis owing to microdamage in the bone. $^{8}$ Ischaemic vasculopathy as part of the underlying disease may also have a role. ${ }^{9}$ However, if these mechanisms are correct, then the association reported here should occur more often than it does. Active vasculitis or mechanical orthopaedic factors were excluded in our case. The absence of pain might be the result of peripheral nerve dysfunction secondary to polyneuropathy caused by previous MCTD associated vasculitis. Glucocorticoid treatment might also have decreased the pain by reducing femoral head synovialitis.

(3) The simultaneous occurrence of osteonecrosis and atraumatic fracture of the femoral neck was even more surprising than the rare occurrence of severe, yet asymptomatic, osteonecrosis. Revascularisation of dead bone begins shortly after interruption of the blood supply. It promotes removal of necrotic bone by osteoclasts while inducing osteoblasts to synthesise new bone, thus creating more stability. The combination of osteonecrosis and fracture in the same region is therefore extremely rare.
In conclusion, osteoporosis is a common side effect of glucocorticoid treatment, and early prevention and treatment are necessary. Osteonecrosis and osteoporosis with a fracture in the same area as the side effects of glucocorticoid treatment is extremely rare. Only imaging techniques will allow differentiation.

Authors' affiliations

K Loddenkemper, C Perka, G-R Burmester, F Buttgereit,

Departments of Rheumatology/Clinical Immunology and Orthopaedics,

Charité University Hospital, Humboldt University of Berlin, Germany

Correspondence to: Dr K Loddenkemper, Department of

Rheumatology/Clinical Immunology, Charité University Hospital,

Schumannstrasse 20-21, 10117 Berlin, Germany:

konstanze.loddenkemper@charite.de

Accepted 27 December 2001

\section{REFERENCES}

1 Ficat RP. Idiopathic bone necrosis of the femoral head: early diagnosis and treatment; J Bone Joint Surg Br 1985;67:3-9.

2 Anonymous. Recommendation for prevention and treatment of glucocorticoid-induced osteoporosis. American College of Rheumatology Task Force on Osteoporosis Guidelines. Arthritis Rheum 1996:39:1791-801.

3 Adachi JD, Bensen WG, Brown J, Hanley D, Hodsman A, Josse R, et al. Intermittent etidronate therapy to prevent corticosteroid-induced osteoporosis. N Engl J Med 1997;337:382-7.

4 Steinberg ME, Brighton CT, Steinberg DR, Tooze SE, Hayken GD. Treatment of avascular necrosis of the femoral head by a combination of bone grafting, decompression, and electrical stimulation. Clin Orthop 1984; (186):137-53.

5 Desforges JF. Nontraumatic necrosis of bone (osteonecrosis). Review article. N Engl J Med 1992;326:1473-9.

6 Pavelka K. Osteonecrosis. Baillieres Best Pract Res Clin Rheumato 2000;14:399-414.

7 Felson DT, Anderson JJ. A cross-study evaluation of association between steroid dose and bolus steroid and avascular necrosis of bone. Lancet 1997;i:902.

8 Manolagas SC, Weinstein RS. New developments in pathogenesis and treatment of steroid-induced osteoporosis. J Bone Miner Res 1999; 14:1061-6

9 Akiyama K, Hirota J, Taniyasu N, Asano S. Unusual complications in an inflammatory abdominal aortic aneurysm. Jpn Circ J 1999;63: 914-16. 